erythema infectiosum. A brief description of this minor epidemic was published in $1954 .^{1}$ From time to time I have seen the odd example of this exanthem, but $I$ have never seen two cases in one house nor, until last month, have I been able to detect the infection of one child by another. On 9 September I saw a girl aged 8 with the typical red face, rubella-like arm rash, but no enlarged lymph nodes and no constitutional upset. On 27 September I saw her friend, aged 7, with the same clinical picture. The two girls are constant companions. It is just possible that there was a cross-infection here with an incubation period of some 18 days. - I am, etc.,

Ibstock, Leics

C. A. H. WATtS

1 Watts, C. A. H., Lancet, 1954, 1, 573.

\section{Challenge to the Profession}

SIR,-Dr. D. Morley's admirable paper (12 October, p. 85) introduces a challenge to the medical profession. Not only have doctors failed to solve the health problems of the less developed countries-in spite of their ever-increasing skills and technology-but, because of these very skills, they have actually hindered the application of appropriate solutions to these countries' health problems. When Ivan Illich said provocatively to a Scottish medical gathering recently that within the last decade the medical establishment had become a major threat to health ${ }^{1}$ he was expressing what $I$ believe to be a profound truth.

The medical profession dominates the field of health planning. Our professionalism and exclusiveness dictate that only doctors are able to make decisions on health priorities and it is assumed that the doctor is automatically the "leader" of the health team. This has led to expensive medical training programmes everywhere in the world and institutionalized medical care systems inappropriate to the health needs of most of the people. Doctors are increasingly expensive to train and thus more expensive to employ. Because they have been "elegantly" trained, as Fendall has so aptly described it, ${ }^{2}$ with supportive and ancillary services they will naturally not want to work in an "inelegant situation" without these, hence the urban migrations and the worldwide brain drain. You cannot expect doctors, as we now recognize and train them, to work in rural health centres. It is naive to think that they will-if only we add more preventive medicine and community health to their training curricula. Even in Tanzania, recognized as having a particularly enlightened policy towards rural health development, the curriculum, with its continuing emphasis on basic sciences, bears little relationship to what is stated to be the job of a Tanzanian rural district medical officer. I think it is impossible to train doctors to do the work we now expect them to do without drastically revising our concept of what we are training doctors for.

All countries stress the need for more doctors, but nowhere has it been shown on what criteria this need is based. Many less developed countries started medical auxiliary training schools which have been or are to be "upgraded" to medical schools because international pressure from "the profession" and its exclusive professional bodies require that recognition can be given only when certain "standards" are met. So, increasingly, all countries aspire to train more highlyskilled personnel less able to meet the basic health needs of the ordinary people. Even the British Health Service is crumbling because we are overtraining primary medical care personnel to such an extent that we cannot afford enough of them. The U.S.S.R. has twice as many doctors per head of population (trained differently and for a shorter period). China has one "barefoot doctor" to every 200 people. For any health service system to have an impact on health there must surely be a high ratio of primary care personnel to population. The more skilled and expensive the doctors are the fewer there will be and the more inappropriate they will be for the job of caring for people at the primary care level. What all countries need is large numbers of people able to recognize and manage the common community diseases, to know the families under their care, to screen for and prevent disease, and, above all, to counsel. It does not take six to eight years to train people to do this.

Do we as a profession have the courage and the vision to recognize that we are right out of step with the health needs of the world?-I am, etc.,

Susan M. Cole-King

Institute of Development Studies,

University of Sussex,

1 Guardian, 1974, 28 September.

Fendall, N. R. E., Auxiliaries in Health Care: Programs in Developing Countries. Baltimore, Johns Hopkins Press, 1972.

SIR,-Paul Ehrlich pointed out that to face honestly the need for population control may "expose one to the painful criticism of being both anti-people and anti-poor"-prophetic words indeed! They are quoted in Ivan Illich's deeply stimulating book Tools for Conviviality, ${ }^{1}$ which every doctor should read. If they did I think we would see that the Health Service crisis is one partly at least of our own making. He argues that we have taken away the burdens of birth and death from the home and the family and transferred them to the increasingly expensive hospital ward. Instead, he says, we should be teaching people to care for each other and that doctors cannot work miracles. Unfortunately it is easier to give $£ 50$ worth of vincristine than to explain what people are unwilling to accept.-I am, etc.,

\section{Brigg, Humberside}

M. C. WIILIS 1 Illich, I., Tools for Conviviality. New York,
Harper, 1973.

\section{Calf Haematoma}

SIR,-I was interested to read the paper by Dr. D. A. Tibbutt and Mr. A. J. Gunning entitled "Calf Haematoma: A New Sign in Differential Diagnosis from Deep Vein Thrombosis" (26 Ootober, p. 204).

In my experience and that of other general practitioners and indeed of our practice nurse, this sign is exceedingly common. Naturally, very few of these cases find their way to hospital, being treated in general practice by masterly inactivity.
The publication of this paper illustrates the limited clinical experienoe of hospital doctors and is further evidence that those considering a specialty should spend some time in general practice in order to gain experience of the $90-95 \%$ of illnesses treated at home.-I am, etc.,

A. J. EARL

Barrow-on-Soar,

\section{Full View of the Road}

SIR,-Professor R. A. Weale (19 October, p. 149) has quite rightly suggested that all optical devices should be clear if used for night driving.

While the scientific logic of such a statement must be recognized, the public ought to know that many of the light tints they have on contact lenses, spectacles, and windscreens fall within the $85 \%$ transmission level. There is therefore no need for them to panic and change their appliances but only to seek advice from their practitioner on the next suitable occasion.

Professor Weale's interpretation of section 22 of the Motor Vehicles (Construction and Use) Regulations 1973 requires further discussion. Full view, I agree, should be interpreted as full field as well as minimal interference with acuity, but the practicality of making a perfectly transparent, distortionfree, toughened or splinterproof windscreen of large size and curved must not be ignored. I am sure Professor Weale's message would have been more forceful if he had insisted that on no account must "sunglasses," including polaroid, be worn at night, and this includes all windscreens and side windows tinted to a similar density.

The only other point to which I am sure Professor Weale has the answer is the use of antiglare yellow glasses. I had understood that the use of monochromatic light within the yellow-green range, coupled with good ill'mination, was helpful to decrease the diffraction of light caused by mists and fogs. The problem was not solely that of illumination. Ideally, if we could afford the cost, all our roads should be illuminated.-I am, etc.,

MONTAgue RUBEN

Contact Lens and Prosthetics Department,

Moorfields Eye Hospital,
London W.C.1

\section{Agoraphobia}

SIR,-I would like to comment on your leading article on agoraphobia (26 October, p. 177), particularly your brief review of treatment. It seems to me misleading to equate the benefits of modified leucotomy, 1 suitable for fewer than $2 \%$ of patients presenting with agoraphobia, with desensitization, which is available to all but which is dismissed in your article as producing poor results-the evidence for this assertion being based on a prospective survey of 20 patients treated by graded retraining together with systematic densitization. ${ }^{2}$ According to the authors most patients in this survey "were left with considerable residual disability." It was noted, however, that about threequarters of their patients suffered from sexual difficulties, mainly frigidity, and they concluded that one of the reasons for the 